\title{
Out-of-Pocket and Catastrophic Expenditure of Neonatal Health Care in Kaski District, Nepal
}

\author{
Chiranjivi Adhikari ${ }^{1}$, Bishnu Prasad Sharma ${ }^{2}$ and Sudarshan Subedi ${ }^{1}$ \\ ${ }^{1}$ Pokhara University, School of Health \& Allied Sciences, Public Health Programs \\ ${ }^{2}$ Associate Professor, Tribhuvan University, Patan Multiple Campus, Nepal \\ Correspondence: Chiranjivi Adhikari \\ Email: chiranadhikari@gmail.com \\ Contact No: +977-9851192200
}

\begin{abstract}
Neonatal mortality is the prime indicator that contributes to child mortality. The out-of-pocket $(O O P)$ expenditure fortreatment remains a major barrier in treatment. The study aimed to calculate OOP of neonatal health care in Kaski district of Nepal. A total of 450 mothers (226 from rural and 224 from urban), having infants aged six months or less or the infants died within last six months, were interviewed face-to-face retrospectively for neonate period. Firstly, six out of 33 urban and ten out of 43 rural clusters were randomly selected from Kaski district and secondly, within each cluster, HHs were selected using EPI method as described by WHO. The mean out-of-pocket expenditure (OOP) of neonatal health care was NRs. 4,322 which was 2.7 percent of total non-food expenditure. Three percent HHs suffered catastrophic health expenditure due to neonatal OOP. It reached five percent when housing/rental cost was excluded from non-food expenditures. HHs with cases of ARI, diarrhea, and others such as Neonatal Tetanus (NT), constipation, eye infection, preterm, meconium engulf and allergy differed significantly from the HHs with cases of jaundice and fever at all three thresholds of catastrophic health expenditure. OOP also differed significantly according to the levels of health facilities.
\end{abstract}

Key words: out-of-pocket; catastrophic; neonatal; cost; Nepal

\section{INTRODUCTION}

Neonatal mortality rate (NMR) is 33 per thousand and two and half times more than post-neonatal mortality(MOHP/Nepal, 2012). Despite tremendous efforts from public and private sectors, it is not decreasing as expected in comparison with the pace of that of post-neonatal and child mortality during the period 2001 and 2011. This impedes achieving the millennium development goal 4 (MDG 4). Neonatal mortality is higher among infants born to mothers in rural areas, least wealthy households, and socially disadvantaged castes and ethnic groups. Similarly, neonatal mortality rates are particularly high for babies born to mothers with no education 
or to mothers who are young (under age 20) or old (over age 35), who had a low body mass index, or are of short stature as well as have babies with less than twoyear birth intervals, those born to mothers with poor birth preparedness practices, or who had made few antenatal care visits, and babies who had poor immediate new-born care. Also, neonatal mortality is higher among babies born in households with indoor air pollution or in households without access to improved water and sanitation facilities, and among babies born to mothers who are not exposed to public health broadcast media(MOHP/Nepal, 2012). Most of the factors among these are directly or indirectly related to cost that the households should pay for their neonates' health protection. The out-of-pocket (OOP) payments by families can include fees for consultations, the cost of drugs, travel and supplies. Community-based integrated management of childhood illness (CB-IMCI) program evolved in Nepal since 1999 with an aim of addressing the major childhood illnesses by government of Nepal. The program covered all 75 districts since 2009/2010. CB-IMCI includes management of infection, jaundice, hypothermia and counseling on breastfeeding for young infants less than 2 months of age.

Since more than half neonates get morbid(Srivastava et al., 2009) and it is higher in early neonatal period(MOHP/Nepal, 2012), it is recommended to get neonates checked within first three days of birth. Those who get checked and do not get checked within first three days of birth had $30 \%$ and $70 \%$ mortalities respectively(MOHP/Nepal, 2012). Mortality also varied according to place of residence. It was 34 and 23 per thousand in rural and urban respectively(MOHP/Nepal, 2012).

It is not clear from the literature whether the income and other variables determine the choice of facility the mothers take their neonates for treatment. Additionally, the outcomes by types of facility are also not clear and the variation of OOP is not well documented with and without CB-IMCI in Nepalese context.

The treatment seeking behavior is shaped by perceived and real quality of services provided by different levels of health care facilities. However, this study aimed to analyse this behavior based on the capacity to pay (indirectly measured as a share of their non-food expenditure) and other socio-demographic factors. The OOP expenditures is assumed to differ according to different levels of health care.

The aim of this study was to estimate the out of pocket expenditure (OOP) of neonatal health care by level of health facilities and analyse the proportion of households incurring catastrophic health expenditure due to OOP payments. The ethical approval was obtained from Nepal Health Research Council (NHRC). Written consent from mothers was taken prior to interview. All the principles and norms of 
Helsinki declaration was followed for the maintenance of dignity and assurance of confidentiality of the respondents.

\section{LITERATURE REVIEW}

Almost $4 / 5^{\text {th }}$ share of the population of Nepal live in rural areas. The impoverishing effect of OOP expenditure in health is higher in rural and affluent society (Garg and Karan, 2009). About 55 percent share of total health expenditure (THE) in 2005/06 was spent OOP in Nepal (Shrestha, Gauchan et al. 2012). Despite this, the Ministry of Health and Population of Nepal observed that the investment in maternal, child and new-born health care directly contributes to the living standard of households (HHs, hereafter). Nepal, like five other South Asian counties; spends just US\$26 per capita per year on health - from both domestic public and private sources and international development assistance. Similarly, average additional cost for Nepal for maternal and new born health care interventions in the period 2009-2015 was only US\$ 1.76 (WHO, 2012).

OOP differs according to societies and affluence. In the Indian context, it constituted 4.8 percent of total consumption expenditure, which is equal to 10.7 percent of total non-food expenditure. The proportions are lower in urban areas than in rural areas. The proportion of OOP payments in household total as well as non-food expenditure increases with an increase in levels of consumption expenditure both in rural and urban areas. This progressive nature of OOP expenditure is more pronounced in rural than in urban areas(Garg and Karan, 2009).

The catastrophic health expenditure can be explained both from the percent of total income (or more clearly pronounced by expenditure) and the capacity to pay of a household. The latter is defined as the effective income remaining after basic subsistence needs have been met. The expenditure better reflects the $\mathrm{HH}$ welfare than does the income in $\mathrm{HH}$ surveys. Earlier, five to 20percent of total expenditure used to be taken as catastrophic. Xu enumerated that 40percent of capacity to paycan also be taken as catastrophic (Xu et al., 2003).

Percentage of HHs capacity to pay out of pocket expenditure in health in China was 18.5 (ranging from 22.2 percent among the poorest to 14.9 percent among the richest quintile. Similarly, 13 percent $\mathrm{HHs}$ (ranging from 15.8 percent among the poorest to 10.7 percent among the richest quintile) were incurring catastrophic health expenditure. catastrophic health expenditure incurred among 14.3 percent due to the health expenses of all under five children; whereas it was more pronounced in rural areas than urban (15.8 percent vs. 7.9 percent among the under-fives; Li et al., 2012). 


\section{METHODOLOGY}

The study was community-based cross-sectional and mainly descriptive using quantitative methods. Primary data was collected from 10 out of 43 VDCs and six out of 33 wards of two municipalities of Kaski district. Some secondary data from the report of NLSS 2010/11 were also utilized.

The sampling frame for clusters was developed from the list of VDCs and wards of municipalities from District Public Heath Office (DPHO) Kaski's target for the fiscal year 2014/15. As a result, the frame for rural and urban clusters comprised of 43 and 33 clusters respectively. The frame of eligible respondents was estimated based on assumption of 1.5 percent of population under six months(Magnani, 2007); 4.5 and 4.1 were the average household size(MOHP/Nepal, 2012) of rural and urban settings. Total households in urban and rural were 84,914 and 39,843 respectively. Similarly, the population under six months was 5222 and 2689 in 33 urban and 43 rural clusters respectively. The average number of neonates was 158 and 63 in urban and rural clusters respectively.

Kaski district possesses a total population of 492,098(CBS 2012). The district was stratified into rural and urban settings. Then systematic random selection of cluster samples with probability proportional to size (PPS) was applied in rural and urban strata based on disproportionate allocation between strata analysis so as to compare rural and urban strata.

By applying $n=z^{2} \sigma^{2} / d^{2}$, the sample size was calculated as $431.1(\sim 432)$ taking $\mathrm{sd}(\sigma)=119$ based on a study by Ekwochi et al., where they found the average cost of managing neonatal illness in Nigeria in 2013 was US\$223; sd=119) (Ekwochi, Osuorah et al. 2014); margin of random error (d) of \pm 14.5 ; design effect of 1.5 ; and response rate of $90 \%$. Finally, 226 and 224 mothers from urban and rural clusters were taken respectively to be on safe side.

Cluster sampling based on probability proportional to size (PPS) was applied in order to select five each from rural and urban clusters. After generating 320 as random start between 1 and 5222 and the sampling interval as 1044.4, five urban clusters viz. ward number 2, 7, 10 and 16 of Pokhara sub-metropolitan and ward number 4 of Lekhnath municipality were selected. Similarly, generating random start of 11 and sampling interval of 537.8, five rural clusters- Arbavijaya, Dhampus, Hemja, Rupakot and Lwanghalel were selected. However, due to short fall of sampling as targeted in rural clusters, the targeted 45 samples in each cluster were collected from border or nearby VDCs namely Valam for Arbavijaya; Kaskikot and Dhikurpokhari for Lwanghalel; and Puranchaur and Armala for Dhampus. Similarly, short fall of respondents in 
urban cluster of Lekhnath ward no. 4, they were taken from Lekhnath ward no. 5 (See Appendix Fig. 1).

The starting point for household selection in cluster was based on EPI method. Field staff visited the central location of each cluster; determined the first household randomly and then followed the household nearest next. Finally, before leaving the cluster, once again, it was assured that no neonate was left. However, in cases of urban areas, maximum of 45 mothers with neonates were contacted from each clusters adopting convenient sampling method.

The data was collected from Feb 23- March 28, 2015. On the median day, the $12^{\text {th }}$ March, the buying rate per US $\$$ was 100.16 NRs. (US \$ $1=100.16$ NRs) and the selling rate was $100.76 \mathrm{Nrs}$. The exchange rate of US $\$ 1$ on the $15^{\text {th }}$ Aug 2010 (Median day of NLSS 2010/11) was 74.25 Nrs. Hence in order to convert NRs. in 2010 to 2015, they were multiplied by 1.349 (100.16/74.25)(NRB 2015). The exchange rate was needed in order to compare total non-food expenditure, shares of housing and education of Kaski with national data of 3rd NLSS, 2010/11.

Average nominal annual per capita income for Nepalese is NRs. 41,659(CBS 2011). It equals to NRs. 156.11 when calculated for single day if adjusted for monetary value of 2015, March 12(NRB 2015). However, the time for walking was twice and the waiting time was 2.5 times the normal time since the travel time must be conceived as having a negative demand, a consumer's willingness to pay to have less of it(Belenky 2011). The walking time was again multiplied by two to yield two way cost.

The mothers having infants less than six months or the mothers whose child died before completing his/her first month of life within last six months were included in the study. In case of more than one neonate (less than six month) in a household, the younger was taken. The households having no infants or having an infant aged six months or above were excluded from the study.

\section{Research Instrument}

A structured questionnaire was used for data collection. The method for data collection was face-to-face interview. The questionnaire contained four sections- the household information; air, water and sanitation related information; treatment cost and health seeking behavior for neonate and other family members; and expenditures on non-food items. Information related to life insurance and tobacco consumption was also included in first section. Third section included the types of health facility, the treatment and follow-up, and associated direct and indirect costs for neonates and family members. Treatment and health care costs for family members were included 
in sub-section one of the third section. Fourth section was further divided into six sub-sections- expenditure on regular items; on non-regular items; on durable items, on amenities and utilities; on religious and related special events; on education; and on housing or rental cost.

\section{Statistical Analysis}

The analyses were basically descriptive and the unit of analysis was house hold. The data were described as frequency, percent, range, mean and standard deviation based on place of residence. Non-food expenditures of HHs were measured as proxy of capacity to pay. OOP was assessed from direct expenditures such as money spent on fees and medicines (allopathy and traditional), hospital expenses, laboratory and other diagnostic tests; and indirect such as cost of conveyance; cost of waiting and walking time; lodging and food cost including that of all the visitors. The extent of catastrophic payments was assessed using thresholds of $40 \%$ of non-food expenditure, as recently recommended by $\mathrm{WHO}$ (Castillo-Riquelme et al., 2008). Since data were not normally distributed, chi-square tests were used to observe the independence of sociodemographic variables and Kruskal-Wallis test was applied to observe the difference of neonatal health care expenditures based on the levels of HFs and alpha was set at 0.05 . The recall periods for different variables are given in appendix table 1.

Pretest was conducted in Shuklagandaki municipality (declared recently as municipality) of Tanahu district amongst 14 eligible mothers and some modification were made in the study tools. Before and after the pre-test, a one day workshop (orientation and feed-back collection) workshop was conducted for fresh public health graduates appointed as the enumerators. Further, the study is based on scientifically calculated sample size to allow valid comparison with the minimal permissible error $(5 \%)$ committed beforehand the study procedure. Data entry was done in epi-data and analysis was done in SPSS version 20 and MS-Excel. The diagnosis of the illnesses was rigorously assessed with the interaction and further verification with prescription card, if available.

\section{RESULTS}

\section{Socio-demographic Profile of the HHs and S amples}

One out of ten households was headed by female (10\%). Mean family size was 4.4 and number of total HHs was 450 . Almost half (47\%) of the HHs was found to use solid fuel as the major source of energy. Similarly, more than $3 / 4^{\text {th }}(77 \%)$ in rural people were found to use solid fuel as their major source of energy. Less than one percent of the total HHs was found to defecate in open spaces (Table 1). 
Table 1: Socio-Demographic Characteristics of the HHs

\begin{tabular}{|c|c|c|c|}
\hline \multirow[t]{2}{*}{ Characteristics } & \multicolumn{3}{|c|}{ HHs } \\
\hline & Urban (\%) & Rural*(\%) & Total $(\%)$ \\
\hline \multicolumn{4}{|l|}{ Household Headship } \\
\hline Male & $206(91.2)$ & $197(87.9)$ & 403 (89.6) \\
\hline Female & $20(8.8)$ & $27(12.1)$ & $47(10.4)$ \\
\hline \multicolumn{4}{|l|}{ Family size of the HHs } \\
\hline 3 & $85(37.6)$ & $34(15.2)$ & $119(26.4)$ \\
\hline 4 & $84(37.2)$ & $62(27.7)$ & $146(32.4)$ \\
\hline 5 & $34(15.0)$ & $63(28.1)$ & 97 (21.6) \\
\hline$\geq 6$ & $23(10.2)$ & $65(29.0)$ & 88 (19.6) \\
\hline Mean (sd) [Min, Max] & $4.0(1.4)[3,8]$ & $4.8(1.6)[3,9]$ & $4.4(1.5)[3,9]$ \\
\hline \multicolumn{4}{|l|}{ Family Type } \\
\hline Nuclear & $201(88.9)$ & 192 (85.7) & $393(87.3)$ \\
\hline Joint & $25(11.1)$ & $32(14.3)$ & $57(12.7)$ \\
\hline \multicolumn{4}{|l|}{ Sources of Energy Use ${ }^{1}$} \\
\hline Electricity & $221(97.8)$ & $221(98.7)$ & $442(98.2)$ \\
\hline Bio/LP Gas & $223(98.7)$ & $168(75.0)$ & $391(86.9)$ \\
\hline Solid Fuel & $37(16.4)$ & $173(77.2)$ & $210(46.7)$ \\
\hline Solar & $38(16.8)$ & $61(27.2)$ & $99(22.0)$ \\
\hline Kerosene & $1(0.4)$ & $23(10.3)$ & $24(5.3)$ \\
\hline \multicolumn{4}{|l|}{ Sources of drinking water ${ }^{1}$} \\
\hline Improved Source & $246(108.8)$ & $230(102.7)$ & $476(105.8)$ \\
\hline Non-Improved Source & $6(2.7)$ & $0(0.0)$ & $6(1.3)$ \\
\hline \multicolumn{4}{|c|}{ Type of Toilet/Latrine Facility } \\
\hline Improved & $226(100.0)$ & $221(98.7)$ & $447(99.3)$ \\
\hline Non-Improved $^{2}$ & $0(0.0)$ & $3(1.3)$ & $3(0.7)$ \\
\hline Total & $226(100.0)$ & $224(100.0)$ & $450(100.0)$ \\
\hline
\end{tabular}

*Some rural households have been recently included in urban Municipality by GoN ${ }^{1}$ Respondents may report multiple sources, so the sum of sources may exceed actual number and 100 percent.

${ }^{2}$ Including open defecation 
Table 2: Socio-Demographic Characteristics of Sample Population

\begin{tabular}{|c|c|c|c|}
\hline \multirow[t]{2}{*}{ Characteristics } & \multicolumn{3}{|c|}{ Sample population } \\
\hline & Urban (\%) & Rural $^{*}(\%)$ & Total (\%) \\
\hline \multicolumn{4}{|l|}{ Age group } \\
\hline $0-6$ months & 228 & 227 & 455 \\
\hline 6 month-5 years & 101 & 122 & 233 \\
\hline $6-14$ years & 24 & 43 & 67 \\
\hline $15-64$ years & 544 & 645 & 1189 \\
\hline $65+$ & 12 & 46 & 58 \\
\hline \multicolumn{4}{|l|}{ Sex } \\
\hline Male & $454(49.9)$ & $531(53.9)$ & $985(49.4)$ \\
\hline Female & $455(50.1)$ & $550(54.7)$ & $1005(50.5)$ \\
\hline TG & $0(0.0)$ & $2(100)$ & $2(0.1)$ \\
\hline \multicolumn{4}{|l|}{ Occupation } \\
\hline Agriculture & $25(2.8)$ & $168(15.5)$ & $193(9.7)$ \\
\hline Business & $36(4.0)$ & $33(3.0)$ & $69(3.5)$ \\
\hline Service Job & $78(8.6)$ & $55(5.1)$ & $133(6.7)$ \\
\hline Student & $131(14.4)$ & $161(14.9)$ & $292(14.7)$ \\
\hline Labour & $68(7.5)$ & $36(3.3)$ & $104(5.2)$ \\
\hline Housewife & $246(27.1)$ & $234(21.6)$ & $480(24.4)$ \\
\hline Foreign employment & $71(7.8)$ & $132(12.2)$ & $203(10.2)$ \\
\hline Pension & $6(0.7)$ & $11(1.0)$ & $17(0.9)$ \\
\hline Not Applicable & $248(27.3)$ & $253(23.4)$ & $501(25.2)$ \\
\hline \multicolumn{4}{|l|}{ Religion } \\
\hline Hindu & $784(86.2)$ & $943(87.1)$ & $1727(86.7)$ \\
\hline Buddhist & $89(9.8)$ & $64(5.9)$ & $153(7.7)$ \\
\hline Muslim & $9(1.0)$ & $72(6.6)$ & $81(4.1)$ \\
\hline Christian & $27(3.0)$ & $4(0.4)$ & $31(1.6)$ \\
\hline \multicolumn{4}{|l|}{ Educational Attainment } \\
\hline Illiterate & $37(4.1)$ & $83(7.7)$ & $120(6.0)$ \\
\hline Primary & $184(20.2)$ & $274(25.3)$ & $458(23.0)$ \\
\hline Secondary & $182(20.0)$ & $237(21.9)$ & $419(21.0)$ \\
\hline SLC and above & $269(29.6)$ & $243(22.4)$ & $512(25.7)$ \\
\hline Not Applicable (<6 Yrs.) & $237(26.1)$ & $246(27.7)$ & $483(24.2)$ \\
\hline \multicolumn{4}{|l|}{ Ethnicity } \\
\hline Dalit & $166((8.3)$ & $322(29.7)$ & $488(24.5)$ \\
\hline Disadvantaged Janajatis & $229(25.2)$ & $128(11.8)$ & $357(17.9)$ \\
\hline Non-dalitTerai Group & $17(1.9)$ & $5(0.5)$ & $22(1.1)$ \\
\hline Religious Minorities & $7(0.8)$ & $73(6.7)$ & $80(4.0)$ \\
\hline Relatively Advantaged Janajatis & $111(12.2)$ & $126(11.6)$ & $237(11.9)$ \\
\hline Brahmin and Chhetris & $379(41.7)$ & $429(39.6)$ & $808(40.6)$ \\
\hline \multicolumn{4}{|l|}{ Life Insurance Status } \\
\hline Un- insured & $834(91.7)$ & $1055(97.4)$ & $1889(94.8)$ \\
\hline Insured & $75(8.3)$ & $28(2.6)$ & $103(5.2)$ \\
\hline Total & $909(100.0)$ & $1083(100.0)$ & $1992(100.0)$ \\
\hline
\end{tabular}


Agriculture was found to be the major source of occupation for less than one-tenth of the population only. Six percent often people above six years of age wereilliterate and the dalits were the main ethnic group (25\%). Male-female sex ratio was $98 \%$. Very few $(5 \%)$ were insured for life insurance (Table 2).

\section{Frequencies of Neonatal Illness}

At least one neonate in four $(28 \%)$ was found to fall sick in each $\mathrm{HH}$. All the neonates were found to have recovered their first illness, whereas $75 \%$ of them died in their second illness (Table 3).

Table 3: History of Neonatal Illnesses of HHs

\begin{tabular}{|c|c|c|c|}
\hline \multirow[t]{2}{*}{ Variables } & \multicolumn{3}{|c|}{ HHs } \\
\hline & Urban (\%) & Rural*(\%) & Total (\%) \\
\hline \multicolumn{4}{|c|}{ History of Neonatal Illnesses at HHs } \\
\hline Healthy & $168(72.1)$ & $161(71.0)$ & $329(71.6)$ \\
\hline Only $1^{\text {st }}$ Illness & $55(27.9)$ & $62(27.7)$ & $117(27.8)$ \\
\hline Both $1^{\text {st }} \& 2^{\text {nd }}$ Illness & $3(0)$ & $1(1.3)$ & $4(0.6)$ \\
\hline Total & $226(100.0)$ & $224(100.0)$ & $450(100.0)$ \\
\hline \multicolumn{4}{|c|}{$\begin{array}{l}\text { History of result of neonatal illnesses of } \\
\mathrm{HHs}\end{array}$} \\
\hline Result of $1^{\text {st }}$ Illness & $55(100.0)$ & $62(100.0)$ & $117(100.0)$ \\
\hline Alive & $0(0.0)$ & $0(0.0)$ & $0(0.0)$ \\
\hline \multicolumn{4}{|l|}{ Dead } \\
\hline Result of $2^{\text {nd }}$ Illnesses & $1(33.3)$ & $0(0.0)$ & $1(25.0)$ \\
\hline Alive & $2(66.7)$ & $1(100.0)$ & $3(75.0)$ \\
\hline \multicolumn{4}{|l|}{ Dead } \\
\hline Total & $56(96.6)$ & $62(98.4)$ & $118(97.5)$ \\
\hline Alive & $2(3.4)$ & $1(1.6)$ & $3(2.5)$ \\
\hline Dead & & & \\
\hline
\end{tabular}

*Some rural households have been recently included to urban municipality by the GoN.

\section{Types and episodes of neonatal illnesses}

Among the infants in $450 \mathrm{HHs}$ surveyed, less than one third ( $28 \%, \mathrm{n}=121)$ got ill only once during their neonatal period; while less than one percent $(n=4)$ got ill twice. 
During the first illnesses, majority (55\%) suffered from jaundice followed by ARI (26\%). However, during second illnesses, $3 / 4^{\text {th }}$ suffered from ARI (Table 4).

Table 4: Frequencies of First and Second Illnesses of Neonates

\begin{tabular}{lrrrr}
\hline \multirow{2}{*}{ Types of illness } & \multicolumn{2}{c}{$\mathbf{1}^{\text {st }}$ illness } & \multicolumn{2}{c}{$\mathbf{2}^{\text {nd }}$ illness } \\
& Number & \multicolumn{1}{c}{$\%$} & Number & \% \\
\hline Jaundice & 66 & 54.5 & & \\
ARI & 31 & 25.6 & 3 & 75.0 \\
Fever (Systemic Infections) & 8 & 6.6 & & \\
Diarrhoea & 7 & 5.8 & 1 & 25.0 \\
$\begin{array}{l}\text { Others (NT, constipation, eye infection, } \\
\text { preterm, meconium engulf, allergy) }\end{array}$ & 9 & 7.4 & & \\
\hline Total & 121 & 100.0 & 4 & 100.0 \\
\hline
\end{tabular}

\section{Postnatal Regular Check-up and Visit}

Two post-natal visits to health facilities (HFs) are recommended for the neonates by health authorities even in the case of healthy condition. However, less than half $(48 \%)$ neonates met the criteria (Fig 1). The trend-line shows the decreasing number of neonates in both visits compared to first and second visit.

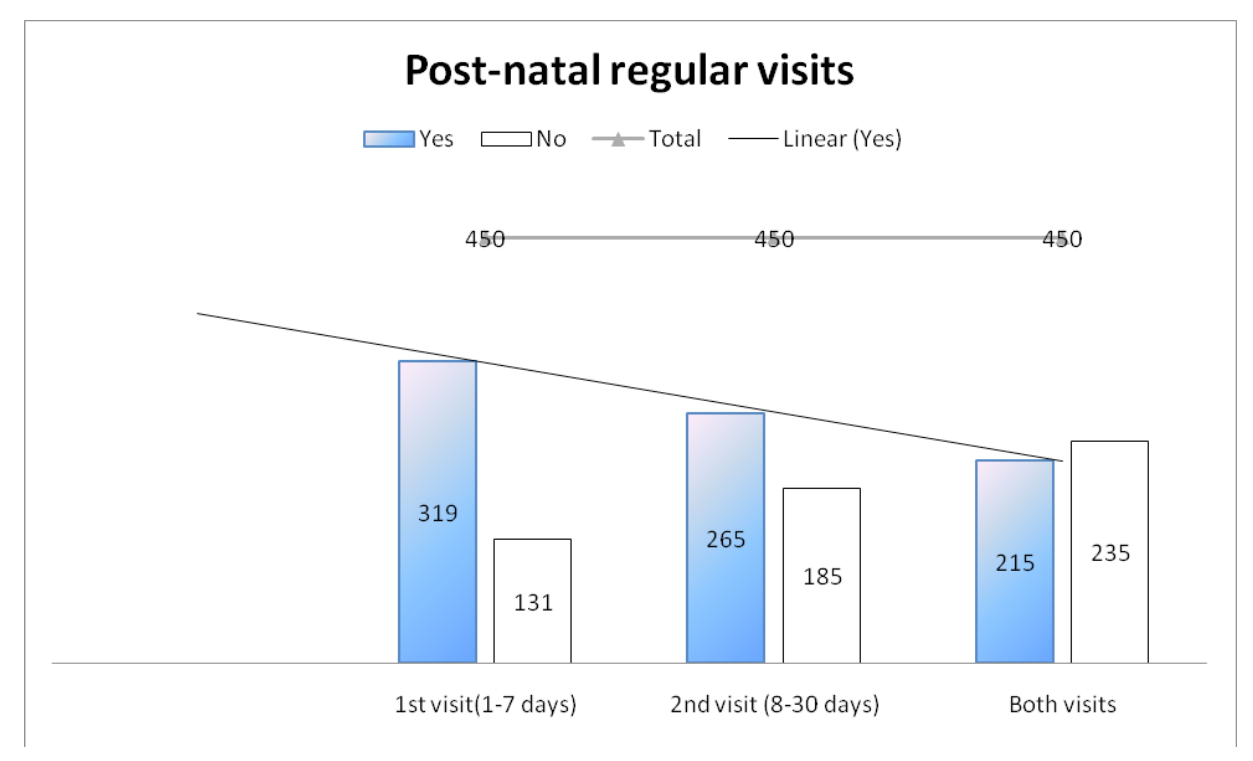

Figure1: Number of Postnatal Regular Visits with Trend Line 
More than nine out of ten (91\%) neonates were taken to PHC level out of total, both post-natal visits of regular care; however, the $1^{\text {st }}, 2^{\text {nd }}$ and both visits did not differ according to HFs ( $\mathrm{p}>0.05)$ (Figure 2$)$.

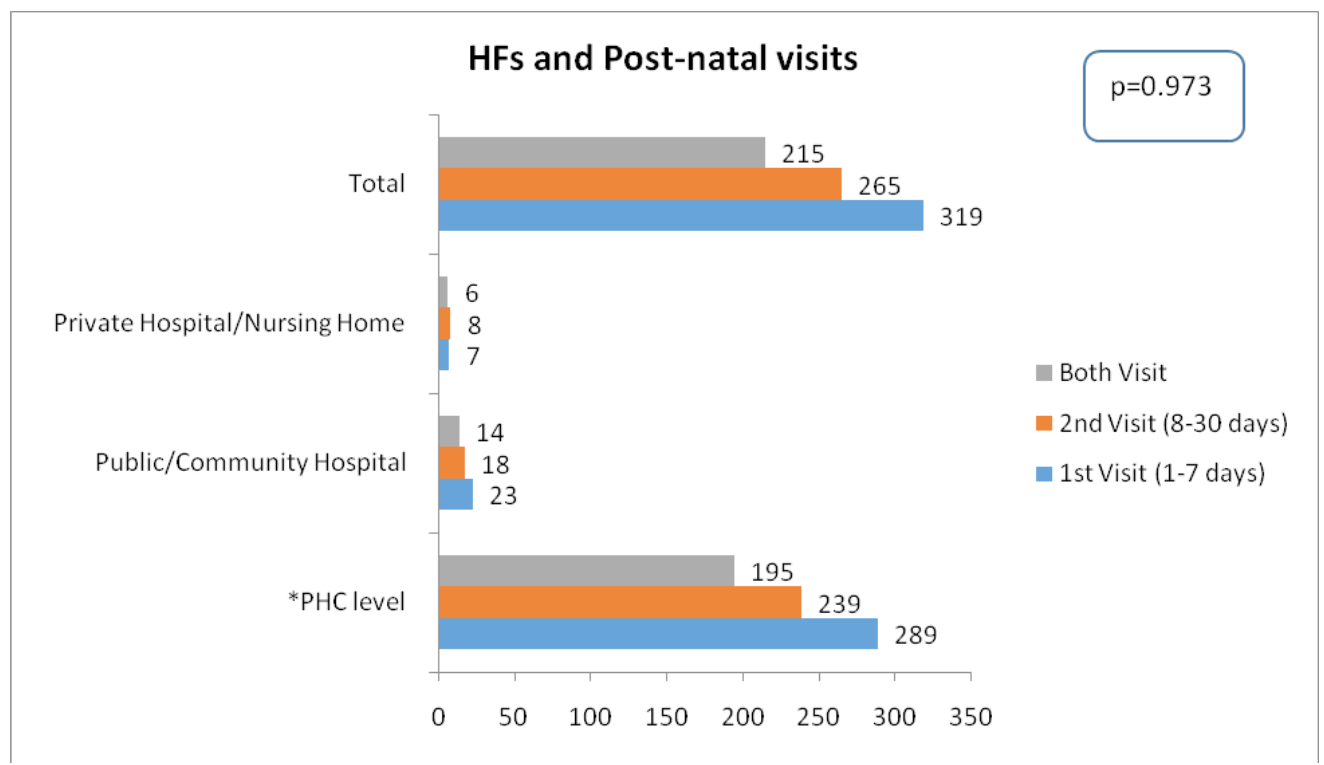

Figure 2: HFs and Frequencies of Post-natal Visits (p-value for chi-square test)

\section{Capacity to Pay of the Households}

Capacity to pay was calculated as a proxy for the non-food expenditures of the HHs. The NLSS 2010/11 (III) entails non-food items as regular and non-regular items (explained as selected non-food in NLSS III); durable goods and utilities; expenses in religious and relatedevents; expenses in smoking and tobacco products; and expenses in education. 
Table 5: Annual Expenditure of Non-Food Items (NRs.)

\begin{tabular}{|c|c|c|c|c|c|c|}
\hline \multirow[t]{2}{*}{ Variables } & \multirow[b]{2}{*}{ Urban $(n=226)$} & \multicolumn{2}{|l|}{ Mean (SD) [range] } & \multicolumn{3}{|c|}{$\begin{array}{l}\text { Share of total non-food } \\
\text { (share including housing } \\
\text { in \%) }\end{array}$} \\
\hline & & Rural (n=224) & Total $(n=450)$ & Urban & Rural & Total \\
\hline Education & $\begin{array}{c}12178.8(18800.3) \\
{[0.0,132000.0]}\end{array}$ & $\begin{array}{c}11179.4(21510.7) \\
{[0.0,168520.0]}\end{array}$ & $\begin{array}{c}11681.3(20178.7) \\
{[0.0,168520.0]}\end{array}$ & $\begin{array}{l}10.8 \\
(6.7)\end{array}$ & $\begin{array}{l}11.2 \\
(7.8)\end{array}$ & $\begin{array}{l}11.0 \\
(7.2)\end{array}$ \\
\hline $\begin{array}{l}\text { *Other } \\
\text { family } \\
\text { member's } \\
\text { health care }\end{array}$ & $\begin{array}{l}347.4(2123.8) \\
{[0.0,23650.0]}\end{array}$ & $\begin{array}{l}335.0(1586.2) \\
{[0.0,18762.2]}\end{array}$ & $\begin{array}{l}341.2(1873.5) \\
{[0.0,23650.0]}\end{array}$ & $\begin{array}{c}0.3 \\
(0.2)\end{array}$ & $\begin{array}{c}0.3 \\
(0.2)\end{array}$ & $\begin{array}{c}0.3 \\
(0.2)\end{array}$ \\
\hline $\begin{array}{l}\text { Smoking } \\
\text { \& tobacco }\end{array}$ & $\begin{array}{c}2090.1(5736.2) \\
{[0.0,47160.0)}\end{array}$ & $\begin{array}{c}3308.1(6331.1) \\
{[0.0,44400.0]}\end{array}$ & $\begin{array}{c}2696.4(6063.7) \\
{[0.0,47160.0]}\end{array}$ & $1.9(1.2)$ & $\begin{array}{c}3.3 \\
(2.3)\end{array}$ & $\begin{array}{c}2.5 \\
(1.7)\end{array}$ \\
\hline $\begin{array}{l}\text { Regular } \\
\text { Items }\end{array}$ & $\begin{array}{l}48999.2(31712.4) \\
{[6804.0,174780.0]}\end{array}$ & $\begin{array}{c}46060.0(35752.2) \\
{[6360.0,394560.0]}\end{array}$ & $\begin{array}{l}47536.2(33778.1) \\
{[6360.0,394560.0]}\end{array}$ & $\begin{array}{c}43.4 \\
(27.1)\end{array}$ & $\begin{array}{c}46.1 \\
(32.0)\end{array}$ & $\begin{array}{c}44.7 \\
(29.3)\end{array}$ \\
\hline $\begin{array}{l}\text { Non-regular } \\
\text { items }\end{array}$ & $\begin{array}{l}33308.6(13649.9) \\
{[4425.0,93425.0]}\end{array}$ & $\begin{array}{l}27363.4(11495.8) \\
{[6000.0,82150.0]}\end{array}$ & $\begin{array}{c}30349.2(12956.4) \\
{[4425.0,93425.0]}\end{array}$ & $\begin{array}{c}29.5 \\
(18.4)\end{array}$ & $\begin{array}{c}27.4 \\
(19.0)\end{array}$ & $\begin{array}{c}28.5 \\
(18.7)\end{array}$ \\
\hline $\begin{array}{l}\text { Durable } \\
\text { goods, } \\
\text { utilities \& } \\
\text { amenities }\end{array}$ & $\begin{array}{c}6446.1(15782.2) \\
{[0.0,170700.0]}\end{array}$ & $\begin{array}{l}5186.7(40333.1) \\
{[0.0,600183.40]}\end{array}$ & $\begin{array}{c}5819.2(30547.7) \\
{[0.0,600183.4]}\end{array}$ & $\begin{array}{c}5.7 \\
(3.6)\end{array}$ & $\begin{array}{c}5.2 \\
(3.6)\end{array}$ & $\begin{array}{c}5.5 \\
(3.6)\end{array}$ \\
\hline $\begin{array}{l}\text { Religious } \\
\text { events }\end{array}$ & $\begin{array}{c}9432.7(10006.9) \\
{[0.0,100000.0]}\end{array}$ & $\begin{array}{c}6484.8(6150.5) \\
{[0.0,40000.0]}\end{array}$ & $\begin{array}{l}7965.3(8434.8) \\
{[0.0,100000.0]}\end{array}$ & $8.4(5.2)$ & $\begin{array}{c}6.5 \\
(4.5)\end{array}$ & $7.5(4.9)$ \\
\hline $\begin{array}{l}\text { Total non- } \\
\text { food }\end{array}$ & $\begin{array}{c}112803.1(60083.5) \\
{[35300.0,387395.0]}\end{array}$ & $\begin{array}{c}\text { 99917.4(69518.7) } \\
{[22420.0,666608.0]}\end{array}$ & $\begin{array}{l}106388.9(65199.0) \\
{[22420.0,666608.4]}\end{array}$ & $\begin{array}{l}100.0 \\
(62.4)\end{array}$ & $\begin{array}{l}100.0 \\
(69.3)\end{array}$ & $\begin{array}{l}100.0 \\
(65.5)\end{array}$ \\
\hline \#Houserent & $\begin{array}{l}67882.3(66616.9) \\
{[1800.0,396000.0]}\end{array}$ & $\begin{array}{l}44215.2(46235.40 \\
{[2400.0,264000.0]}\end{array}$ & $\begin{array}{l}56101.3(58531.2) \\
{[1800.0,396000.0]}\end{array}$ & $(37.6)$ & $(30.7)$ & $(34.5)$ \\
\hline $\begin{array}{l}\text { Total } \\
\text { non-food } \\
\text { (Including } \\
\text { Housing) }\end{array}$ & $\begin{array}{c}180685.4 \\
(105178.2) \\
{[44193.0,723395.0]}\end{array}$ & $\begin{array}{l}144132.6(95395.1) \\
{[26020.0,670208.4]}\end{array}$ & $\begin{array}{l}162490.2(101970.7) \\
{[26020.0,723395.0]}\end{array}$ & $(100.0)$ & $(100.0)$ & $(100.0)$ \\
\hline
\end{tabular}

"Includes only of 3 months period and expenses on illnesses; \#Implicit cost

Mean annual non-food expenditure of each HHs was NRs. 106,389 (sd=65,199). It was NRs. $112,803(\mathrm{sd}=60,084)$ and Nrs. 99,917(sd=69,519) for urban and rural respectively. It increased to Nrs. $162,490(\mathrm{sd}=101,971)$ when housing rent was included. Since literature does not clearly rule out the housing rent as non-food, calculation was done both including and excluding it.The highest share of non-food was taken by housing 
(35\%); followed by regular items (29\%); non-regular items (19\%); education (7\%); and others (10\%) (Table 5).

\section{Out-of-Pocket Expenditure of Neonatal Health Care}

Mean OOP of neonatal health care was Nrs. 4,322(sd=17,385). Direct cost was $3,704(\mathrm{sd}=15798)$ whereas indirect cost was $617(\mathrm{sd}=1,716)$. It was 3,553(sd=11,524) when regular postnatal check -ups excluded. The mean OOP significantly differed according to levels of HFs ( $\mathrm{p}=0.015)$ (Figure 5). It even differed when post-natal regular cost for two visits was excluded $(\mathrm{p}<0.001)$ (Figure. 4), however, there was not significant difference of cost only for post-natal visits in various levels of HFs $(p=0.708)$ (Figure $6)$.

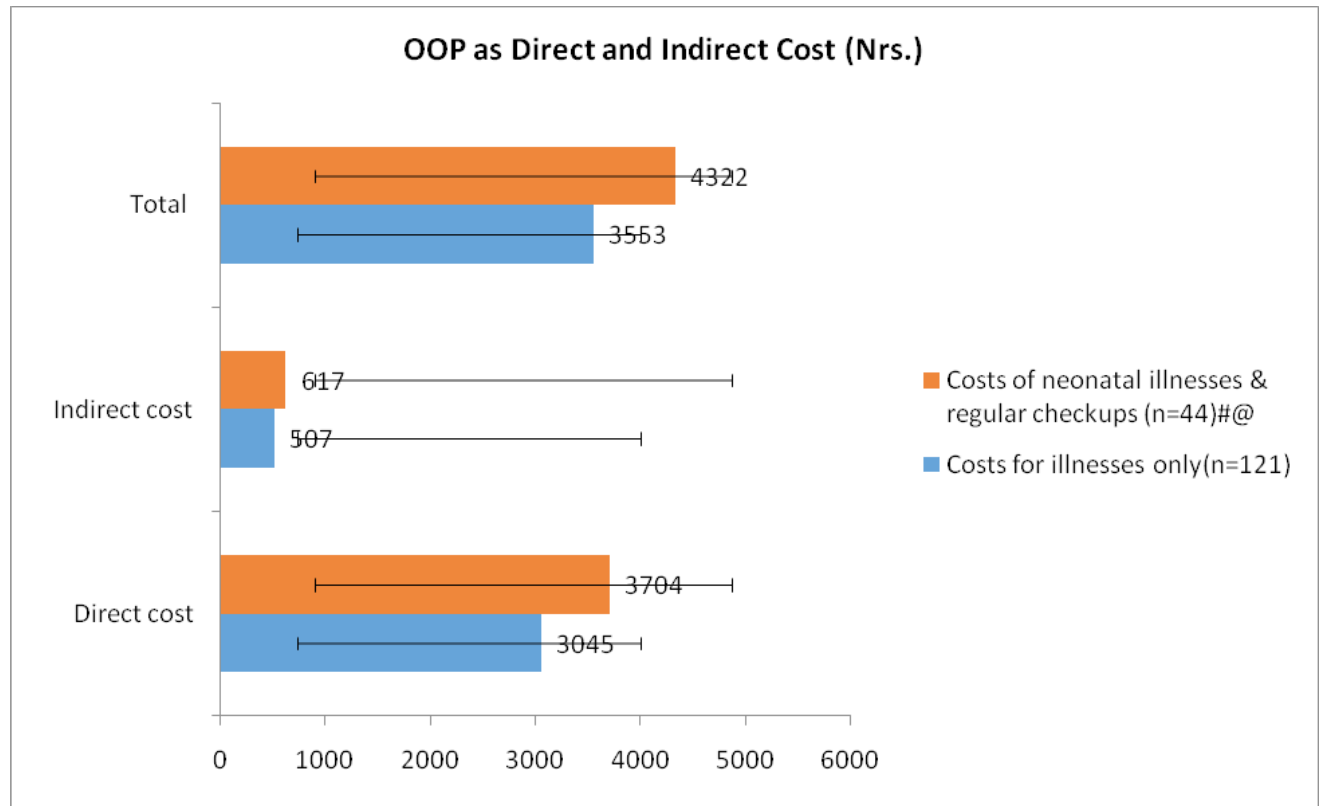

Figure 3: Mean-Direct, Indirect and Total OOP with Error Bars of sd

\# includes 4 cases of twice illnesses; ${ }^{\circledR}$ Indirect cost only for post-natal care 


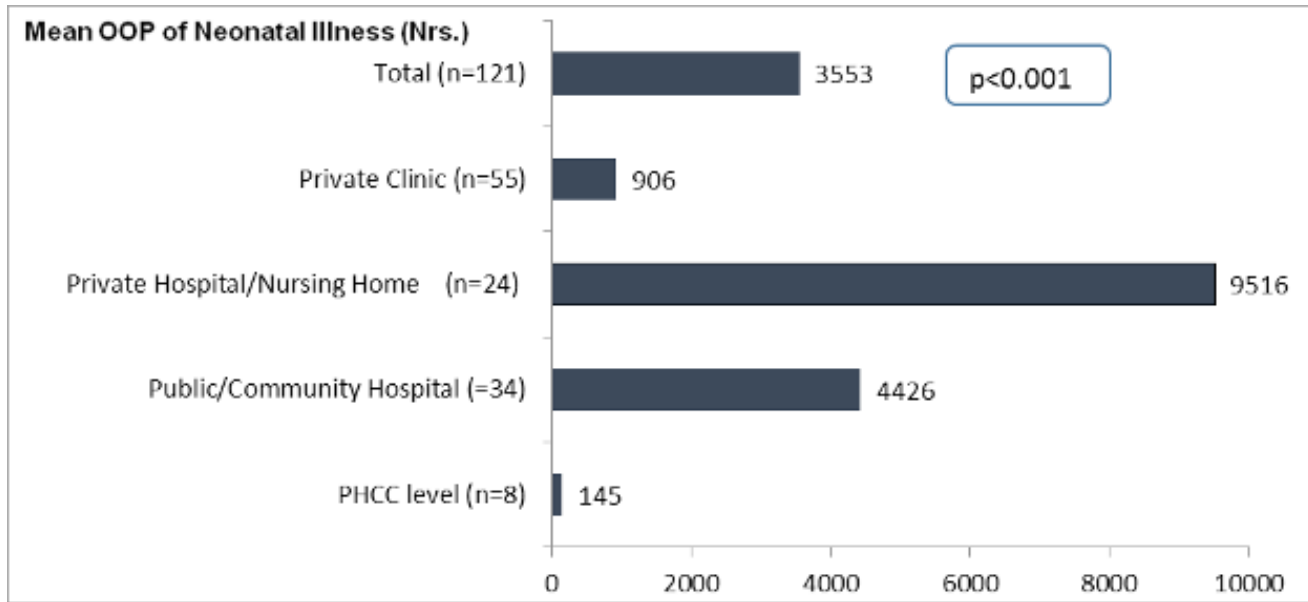

Figure 4: Mean OOP of Neonatal Illness in Different Health Facilities (p-value for Kruskal-Wallis test)

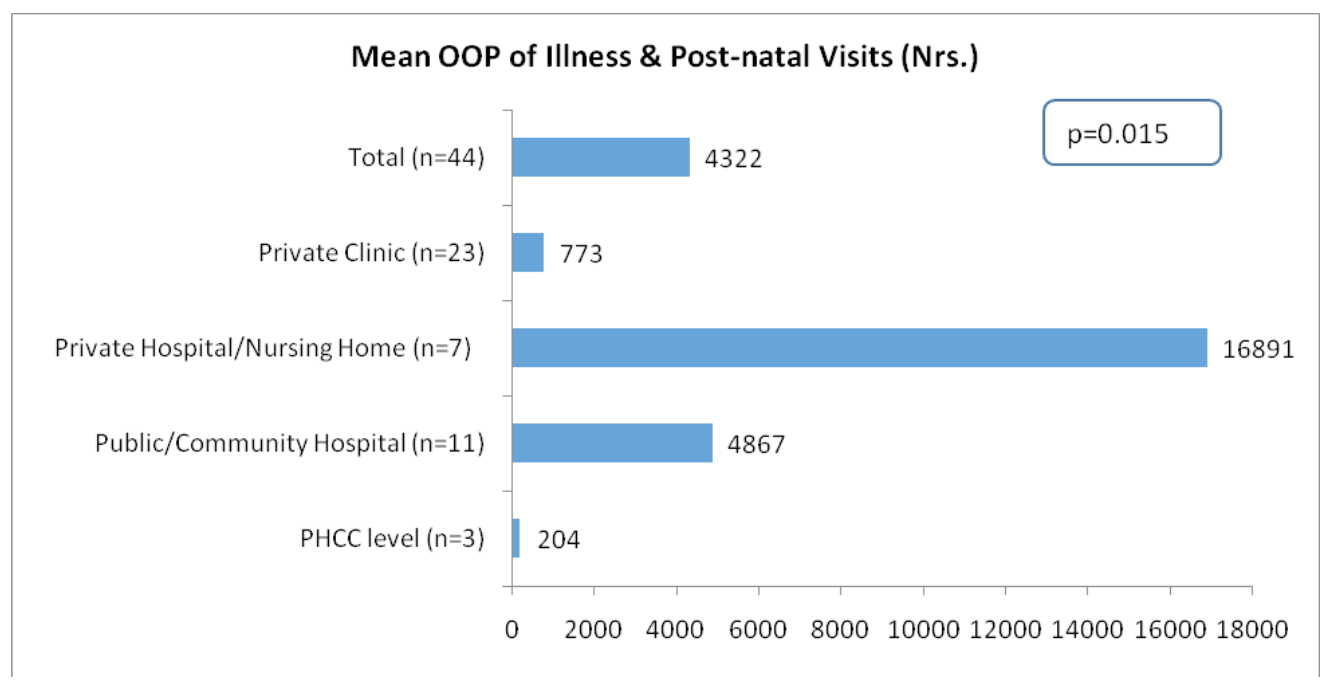

Figure 5: Mean OOP of Neonatal Illness and Two Post-natal Visits in Different Health Facilities (p-value for Kruskal-Wallis test) 


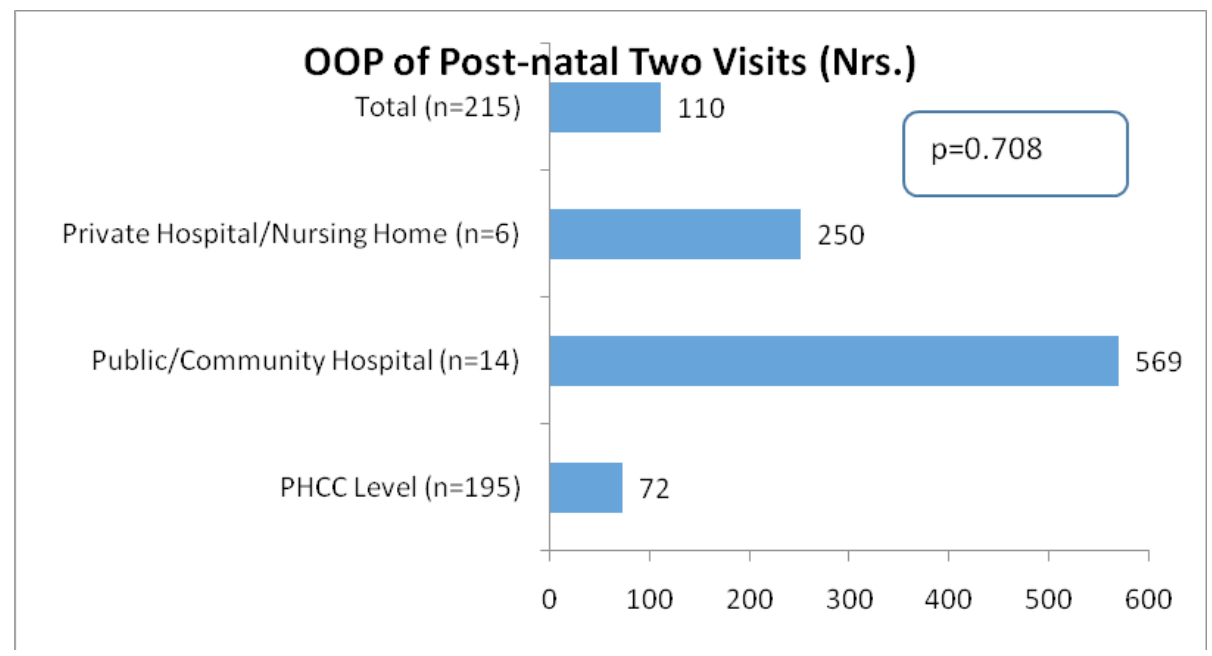

Figure 6: Mean OOP of Two Post-Natal Visits (p-value for Kruskal-Wallis test)

\section{Catastrophic Health Expenditure of Neonatal Health Care and Associated Factors}

Before calculating CHE, the annual expenditure on non-food items was transformed into monthly expenditure. $4.7 \%, 7.1 \%$ and $11.1 \%$. HHs were found to be catastrophic at $40 \% ; 25 \%$ and $15 \%$ cut-off levels respectively due to neonatal expenditure when housing rental cost was excluded. It was found to be $2.9 \%$; $4.9 \%$; and $7.6 \%$ at $40 \%$; $25 \%$; and $15 \%$ cut-offs respectively when housing rental cost was added. (Figure 7).

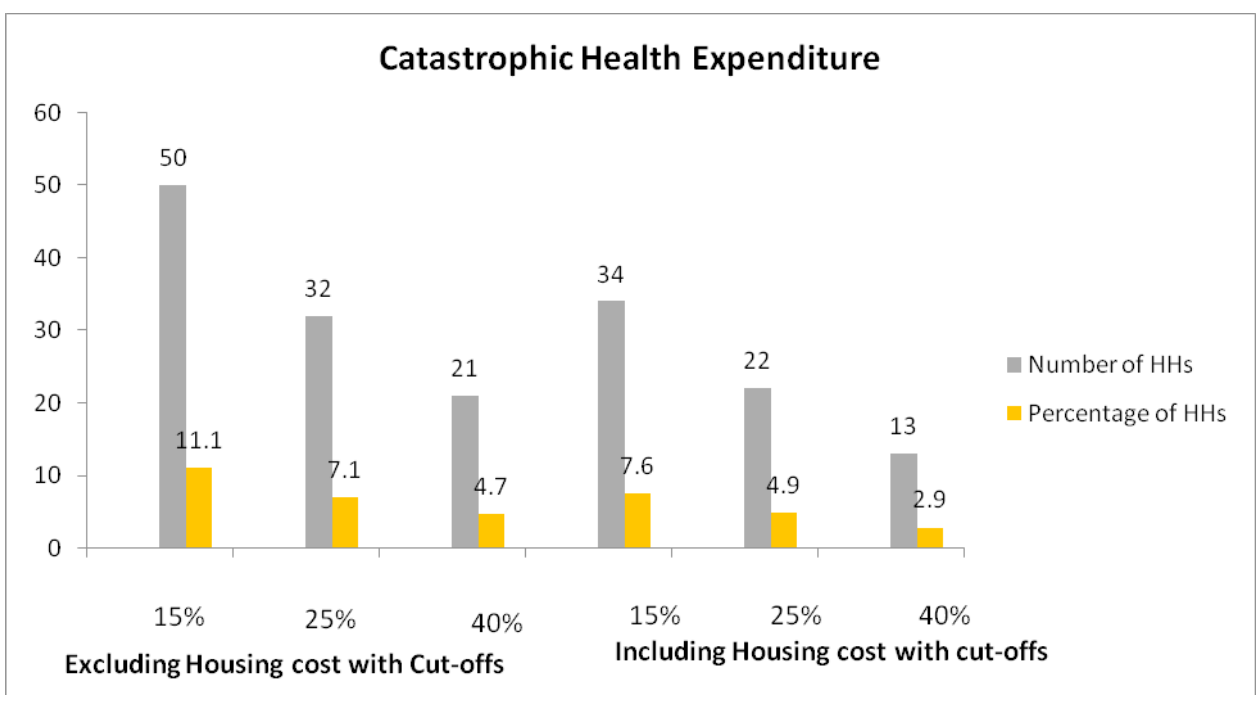

Figure 7: Catastrophic Health Expenditure with Different Cut-offs 
The type of neonatal illness was found to be associated with catastrophic health expenditureat all three $(15 \% ; 25 \%$ and $40 \%)$ thresholds of OOP $(\mathrm{p}<0.001)$. ARI, diarrhea, neonatal tetanus, constipation, eye infection, preterm, meconium engulf and allergy were catastrophic compared to other diseases. However, neither of any other variables were found significant ( $p>0.05)$ (Table 6).

Table 6: Distribution-Sensitive Catastrophic Health Expenditure and Associated Factors

\begin{tabular}{|c|c|c|c|c|c|c|}
\hline \multirow[t]{2}{*}{ Variables } & \multicolumn{2}{|c|}{$15 \%(n=34)$} & \multicolumn{2}{|c|}{$25 \%(n=22)$} & \multicolumn{2}{|c|}{$40 \%(n=13)$} \\
\hline & HH count & p-value & HH count & p-value & HH count & p-value* \\
\hline \multicolumn{7}{|l|}{ Residence } \\
\hline Rural (n=224) & $15(6.7)$ & & $12(5.4)$ & & $5(2.2)$ & \\
\hline Urban $(n=226)$ & $19(8.4)$ & 0.49 & $10(4.4)$ & 0.65 & $8(3.5)$ & 0.49 \\
\hline \multicolumn{7}{|l|}{ Health Facilities } \\
\hline Public $(n=42)$ & $13(31.0)$ & 0.61 & $11(26.2)$ & 0.09 & 7 (16.7) & $0.11^{\#}$ \\
\hline Private $(n=79)$ & $21(26.6)$ & & $11(13.9)$ & & $6(7.6)$ & \\
\hline \multicolumn{7}{|l|}{ Any post-natal checkup } \\
\hline Yes $(n=407)$ & $32(7.9)$ & $0.35^{\#}$ & $22(5.4)$ & NA & $13(3.2)$ & NA \\
\hline No $(n=43)$ & $2(4.7)$ & & $0(0.0)$ & & $0(0.0)$ & \\
\hline \multicolumn{7}{|l|}{ Type of illness } \\
\hline ARI/diarrhoea/Others ${ }^{\oplus}(n=68)$ & $19(27.9)$ & $<0.001^{*}$ & $11(16.2)$ & $<0.001^{* \#}$ & $8(11.8)$ & $<0.001^{* \#}$ \\
\hline Jaundice/Fever ${ }^{\pi}(\mathrm{n}=382)$ & $15(3.9)$ & & $11(2.9)$ & & $5(1.3)$ & \\
\hline \multicolumn{7}{|l|}{ Occupation } \\
\hline Agriculture $(n=106)$ & $9(8.5)$ & 0.68 & $7(6.6)$ & 0.35 & $5(4.7)$ & $0.17^{\#}$ \\
\hline Non-agriculture $(n=344)$ & $25(7.3)$ & & $15(4.4)$ & & $8(2.3)$ & \\
\hline \multicolumn{7}{|l|}{ Religion } \\
\hline Hindu $(n=387)$ & $27(7.0)$ & $0.18^{\#}$ & $17(4.4)$ & $0.18^{\#}$ & $10(2.6)$ & $0.27^{\#}$ \\
\hline Non-Hindu(n=63) & $7(11.1)$ & & $5(7.9)$ & & $3(4.8)$ & \\
\hline \multicolumn{7}{|l|}{ Caste/Ethnicity } \\
\hline Brahmin/Chhetris(n=181) & $11(6.1)$ & 0.33 & $8(4.4)$ & 0.71 & $5(2.8)$ & 0.90 \\
\hline Others $(n=269)$ & $23(8.6)$ & & $14(5.2)$ & & $8(3.0)$ & \\
\hline \multicolumn{7}{|l|}{ Education of $\mathrm{HH}$ head } \\
\hline Above primary $(n=289)$ & $24(8.3)$ & & $14(4.8)$ & & $7(2.4)$ & \\
\hline Total \% & 7.6 & & 4.9 & & 2.9 & \\
\hline
\end{tabular}

${ }^{*}$ Chi-square Test; ${ }^{\#}$ Fisher's exact test; ${ }^{*}$ Significant at 0.01 level; ${ }^{\pi}$ One case of hypothermia included.

${ }^{\circledR}$ Others include NT, constipation, eye infection, preterm, meconium engulf and allergy 


\section{DISCUSSIONS}

The percentage of females as $\mathrm{HH}$ heads in Kaski district was found less than that of national level (10\% vs. $28 \%$ ); however, the proportion was higher in rural area than urban, which is similar with NDHS 2011 report. Mean HH size in the study was found to be exactly similar to that of NDHS report 2011(4.4). It was lower in urban (4.0 vs. 4.1 ) and higher in rural (4.8 vs. 4.5 ) than the national average (Ministry of Health and Population (MOHP) [Nepal] 2012).

Nominal non-food expenditure of Kaski was found higher than that of national and regional level, but lower than that of total national urban and urban hills (except Kathmandu). When compared with NLSS III, the share of housing was found similar to total urban (35\% in both); almost half of western region in case of education (14\% vs. $7 \%$ ); and slightly less with western region in share of other non-food (61\% vs. $58 \%$ ) (CBS 2011). This study revealed $28.4 \%$ of the neonates had some illnesses. A similar study conducted in India had showed $50.3 \%$ of the neonates of having illnesses (Srivastava, Awasthi et al. 2009).

Though OOP expenditure of maternal, new-born and child death has decreased since 2000 , over $40 \%$ is still paid from HH's pocket (SC 2012). The hospital-based study in Nigeria showed that average cost of managing a new-born costs US\$223 (sd=119) and 97\% of OOP payment was catastrophic (Ekwochi, Osuorah et al., 2014). This study revealed that OOP paymentof neonatal health care was NRs. 4322 (sd=17385) (US\$ 43.2, $\mathrm{sd}=173.6$ ); which is 2.7 percent of total non-food expenditure. In a study conducted in Tanzania, Manzi et al. found that among under five children, OOP at government and NGO facilities with IMCI was lower than without IMCI (Tshs.3.5 vs.Tshs.6.9 and Tshs.95.1 vs.Tshs.267.3). When the care was sought at government primary health care, the OOP was on average Tshs. 110.1(Exchange rate; \$US 1=1000 Tshs; currently as Tzs.) (Manzi, Schellenberg et al. 2005).

In the present study, the mean OOP expenditure of neonatal health care for both including and excluding two post-natal regular visits was found to significantly differ according to the levels of HFs (PHC, hospitals and private clinic) ( $p=0.015$ and $p<0.001$ respectively). Similar study conducted in India showed that combined expenditure (medicine, consultation and conveyance) significantly differed according to the levels of HFs (government and non-government practitioners) (Srivastavaet al. 2009). In our study, OOP expenditure of regular post-natal visits twice did not significantly differ according to the levels of HFs ( $p=0.708)$. This might be due to no expenditures found in direct cost for regular visits and the similar distance covered to different levels of HFs. 
Regarding some limitations of the study, Kaski is one of the top ranking districts in terms of per capita income that may not represent the whole country. Recall period for neonatal illnesses was six months which may lead to recall bias. Three VDCs were declared municipality after the study began which may lead to misclassification bias. Respondents were directly searched with snow-ball strategy; as a result, some mothers might have been left from enumeration from the clusters. These might lead to bias in generalization of the conclusion.

\section{CONCLUSIONS}

Our study found thatless than half $(48 \%)$ neonates were sought for twopost-natal regular visits. Out of total HHs; 121 neonates were found to be ill only once and four neonates among them got ill for twice. Mean annual non-food expenditure was Nrs. 162,490 ( $\mathrm{sd}=101,971$ ) (exchange rate; US $\$ 1=100.16$ ). The share of housing cost was more than one-third (35\%). The mean OOP in neonatal health care was NRs. $4,322(\mathrm{sd}=17,385)$ which is $2.7 \%$ of total non-food expenditure. The cost lowered by $18 \%$ (NRs. 3,553) when the cost of regular post-natal care was excluded. Three percent HHs suffered catastrophic impacts from OOP expenditure onneonatal health care as a $40 \%$ of total non-food expenditure. The percentage reached $5 \%(n=21)$ when the housing rent was not included. The mean OOP was found to be significantly different for various HFs (PHC levels; public/community hospitals; and private hospitals or nursing homes). The major health care components in different HFs that incur catastrophic payment should be evaluated and considered in the list of free health care.

\section{Acknowledgements}

This study received financial support from United Nations Children's Fund (UNICEF) Nepal and technical support from Institute for Nepal Environment and Health System Development (INEHD), Nepal. The authors are thankful to mothers of Kaski district, who participated in this study and Ms.AmitaGubhaju and Mr. SushantBuddhacharya for field work.

\section{Competing Interests}

CA received fund to conduct this study from UNICEF. CA consulted INEHD for technical aspects. All the authorshave declared that no competing interests exist.

\section{References}

Belenky, P. (2011). Revised departmental guidance on valuation of travel time in economic analysis. US Department of Transportation. Washington, DC.

Castillo-Riquelme, M., McIntyre, D., \& Barnes, K. (2008). Household burden of malaria in South Africa and Mozambique: is there a catastrophic impact? [Research 
Support, Non-U.S. Gov't]. Trop Med Int Health, 13(1), 108-122. doi: 10.1111/ j.1365-3156.2007.01979.

CBS. (2011). Nepal living standard survey 2010/11: Statistical report. Kathmandu, Nepal: Government of Nepal, National Planning Commission.

CBS. (2012). National population and housing census 2011. National Report. Kathmandu:Author

Ekwochi, U., Osuorah, D. C., Ndu, I. K., Ezenwosu, O. U., Amadi, O. F., Nwokoye, I. C., \& Odetunde, O. I. (2014). Out-of-pocket cost of managing sick newborns in Enugu, southeast Nigeria. ClinicoEconomics and outcomes research: CEOR, 6, 29.

Garg, C. C., \& Karan, A. K. (2009). Reducing out-of-pocket expenditures to reduce poverty: A disaggregated analysis at rural-urban and state level in India. Health Policy and Planning, 24, 116-128. doi: 10.1093/heapol/czn046

Li, Y., Wu, Q., Xu, L., Legge, D., Hao, Y., Gao, L., .. Wand, G. (2012). Factors affecting catastrophic health expenditure and impoverishment from medical expenses in China: policy implications of universal health insurance. Bull World Health Organ(90), 664-671. doi: 10.2471/BLT.12.102178

Magnani, R. (2007). Food and nutrition technical assistance: Sampling guide. Washington, DC: Food and Nutrition Technical Assistance Project (FANTA): Academy for Educational Development.

Manzi, F., Schellenberg, J. A., Adam, T., Mshinda, H., Victora, C. G., \& Bryce, J. (2005). Out-of-pocket payments for under-five health care in rural southern Tanzania. Health Policy Plan, 20 Suppl 1, i85-i93. doi: 20/suppl_1/i85 [pii]10.1093/heapol/ czi059

Ministry of Health and Population (MOHP) [Nepal], N. E., \& ICF International Inc. (2012). Nepal demographic and health survey 2011. Kathmandu, Nepal: Ministry of Health and Population, New ERA, and ICF International, Calverton, Maryland.

NRB. (2015). Nepal Rastra Bank: foreign exchange rate. Retrieved 6/10/2015, from www.nrb.org.np/fxmexchangerate.php

SC. (2012). A decade of change for child survival: Changing the trajectory for our future Executive Summary for Health Policy and Planning Supplement 3. Washington, DC: Newborn Survival Decade of Change Analysis Core Group: Save the Children. 
Sheeran, P., \& Abraham, C. (1996). The health belief model. Predicting Health Behaviour, 2, 29-80.

Shrestha, B. R., Gauchan, Y., Gautam, G. S., \& Baral, P. (2012). Nepal national health accounts, 2006/07 - 2008/09. Kathmandu: Ministry of Health and Population, Government of Nepal.

Srivastava, N. M., Awasthi, S., \& Agarwal, G. G. (2009). Care-seeking behavior and out-of-pocket expenditure for sick newborns among urban poor in Lucknow, northern India: a prospective follow-up study. [Research Support, Non-U.S. Gov't]. BMC Health Serv Res, 9, 61. doi: 10.1186/1472-6963-9-61

WHO. (2012). Investing in maternal, newborn and child health: The case for Asia and the Pacific. Switzerland

Xu, K., Evans, D. B., Kawabata, K., Zeramdini, R., Klavus, J., \& Murray, C. J. (2003). Household catastrophic health expenditure: A multicountry analysis. The Lancet, 362(9378), 111-117. 
Appendix Figure 1. Number of clusters and sample drawn

\begin{tabular}{|c|c|}
\hline \multicolumn{2}{|c|}{ Kaski (43 rural clusters; 33 urban clusters) } \\
\hline 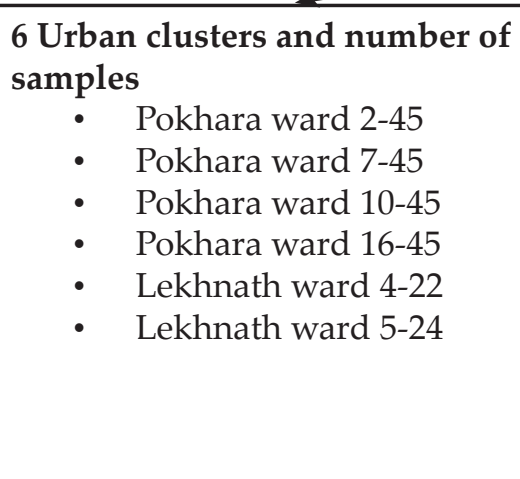 & 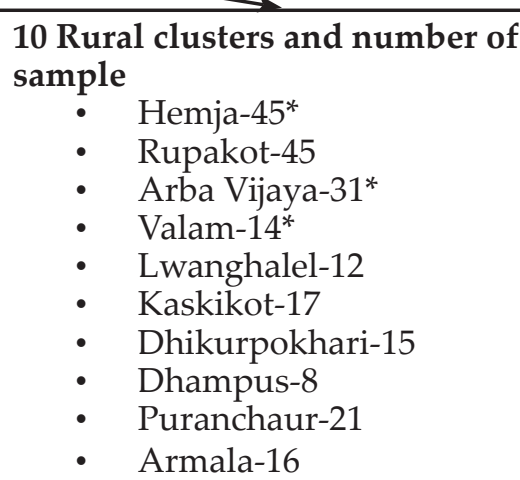 \\
\hline$\downarrow$ & $\downarrow$ \\
\hline Urban subtotal-226 & Rural subtotal-224 \\
\hline
\end{tabular}

*VDCs recently included in Pokhara Sub-metropolitan.

Appendix Table 1. Recall periods of variables

\begin{tabular}{llr}
\hline SN & Variables & $\begin{array}{c}\text { Recall } \\
\text { period }\end{array}$ \\
\hline 1. & Neonatal health status and expenditures & 6 months \\
2. & $\begin{array}{l}\text { Health care expenditures of family member (other than } \\
\text { neonates) }\end{array}$ & 3 Months \\
3. & Expenditure on tobacco products & 1 Month \\
4. & Expenditure on regular consumable items & 1 Month \\
5. & Expenditure on non-regular consumable items & 12 Months \\
6. & Expenditure on durable goods, utilities & 12 Months \\
7. & Expenditure on special/religious/charity & 12 Months \\
8. & Expenditure on education & 12 Months \\
9. & Expenditure on housing/rent & 1 Month \\
\hline
\end{tabular}

